This item was submitted to Loughborough's Research Repository by the author.

Items in Figshare are protected by copyright, with all rights reserved, unless otherwise indicated.

\title{
Large scale PV system monitoring - modules technology intercomparison
}

PLEASE CITE THE PUBLISHED VERSION

http://dx.doi.org/10.1109/PVSC.2010.5615847

PUBLISHER

(c) IEEE

VERSION

VoR (Version of Record)

LICENCE

CC BY-NC-ND 4.0

\section{REPOSITORY RECORD}

Krawczynski, Michal, Matthias Strobel, Brian Goss, N. Bristow, Martin Bliss, Thomas R. Betts, and Ralph Gottschalg. 2019. "Large Scale PV System Monitoring - Modules Technology Intercomparison". figshare. https://hdl.handle.net/2134/7918. 


\title{
LARGE SCALE PV SYSTEM MONITORING - MODULES TECHNOLOGY INTERCOMPARISON
}

\author{
M. Krawczynski, M. B. Strobel, B.Goss, N.Bristow, M.Bliss, T.R.Betts, R. Gottschalg \\ Centre for Renewable Energy Systems Technology (CREST), Department of Electronic and Electrical Engineering, \\ Loughborough University, Loughborough, Leicestershire, LE11 3TU, UK Tel.: +44 1509635311 , Fax: +44 1509 635301
}

\begin{abstract}
This paper presents an initial analysis of a large scale PV system monitoring campaign. Ongoing project aims to be a detailed inter-comparison of different modules technologies installed in a different types of climates, identifying optimal configurations in different climatic zones. Detailed description of created plants and developed monitoring facilities was shown. Appropriate performance indicators are discussed and applied to the measurements of two sites. The resulting performance analysis of different modules technologies, is presented and discussed. Differences between crystalline and thin film technologies were marked, with thin film technologies not performing as well as expected. This is most likely due to installation issues and will be rectified in the near future.. Further investigations will be undertaken and reported in close future.
\end{abstract}

\section{INTRODUCTION}

Photovoltaics are typically sold on a rated power (kWp, i.e. power measured at standard test conditions) basis. This makes it difficult for a user to evaluate the true potential of competing products. Given the progressing commercialization, many products promise enhanced performance under certain conditions. These may not be seen in reality as systems operate in a variety of different operating conditions and modules are only one component out of many making up an entire system .PV modules are meant to work efficiently for a long period of time. Common warranty periods are 25years. Risk of the system failure is not only dependant on components reliability, but it is also a function of time and system complexity. Faulty or underperforming components may stay nonreplaced for long periods of time causing avoidable loses of energy. A comprehensive system monitoring reinforces reliability of the PV plants and can easily detect catastrophic failures. This can be investigated based on the performance ratio index $(P R)$, which is the ration of final $\left(Y_{F}\right)$ and reference $\left(Y_{R}\right)$ yield of a plant (both defined later on). Detailed analysis of this may then be used for more proactive maintenance. General knowledge of system design and manufacturers specified parameters should be sufficient to estimate final yield of the PV plant. In reality it is not true, as design and installation may be affected by unforeseen issues. They need to be resolved during the system commissioning, but this requires sometimes a relatively detailed initial analysis of monitoring data. IKEA is a major retail chain with a large number of stores world-wide. In a drive to enhance the sustainability of these, using photovoltaics for green energy generation has a prominent position. This would allow utilising largely unused roof spaces for the installation of PV devices. The questions are what technology and system design to choose to maximize the performance of such systems. Given the international presence, a worldwide project was initiated, managed by Perpetual Energy and with scientific input from the Centre for Renewable Energy Systems Technology (CREST) at Loughborough University.. Four 250kWp PV plants consisting of different technologies were installed and being instrumented. Location of the plants installation was shown in Figure 1.

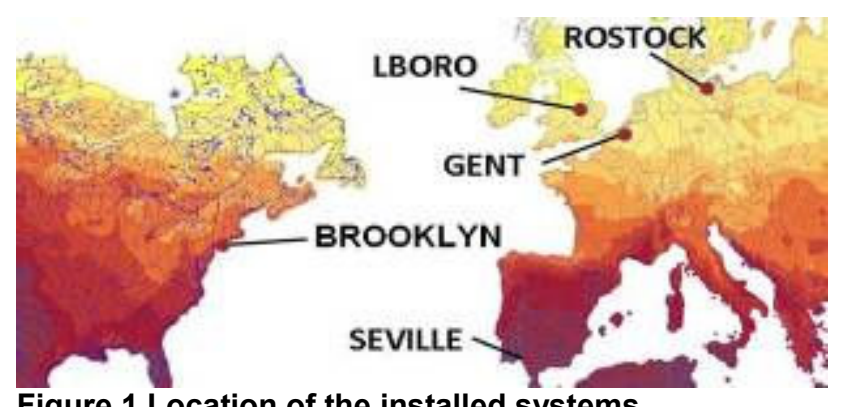

Figure 1 Location of the installed systems.

Rostock and Gent plants are currently operational for more than 10 months. Two similar plants located in Brooklyn and Seville will become operational in the near future. In addition, environmental monitoring systems and sets of reference modules were installed in Loughborough. The wide spread of the location allows to investigate modules performance in a broad set of conditions.

\section{EXPERIMENTAL SETUP}

Dedicated PV monitoring equipment is part of the design. Simplified layouts of the AC and DC subsystems are shown in Figure 2 and Figure 3.

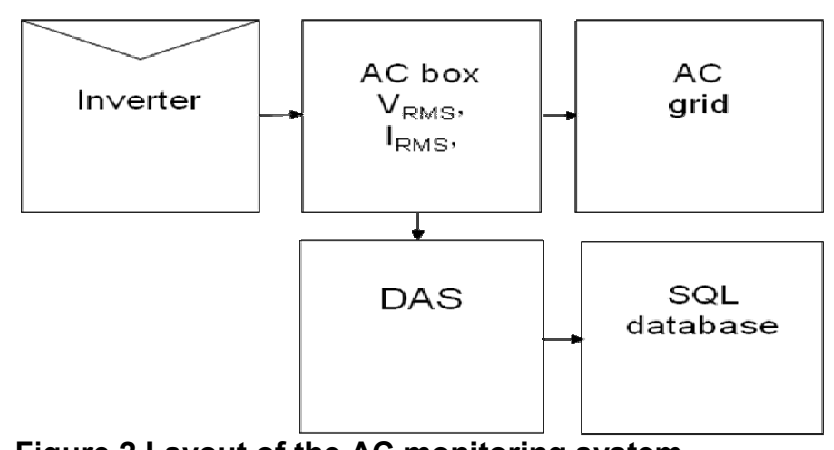

Figure 2 Layout of the AC monitoring system 


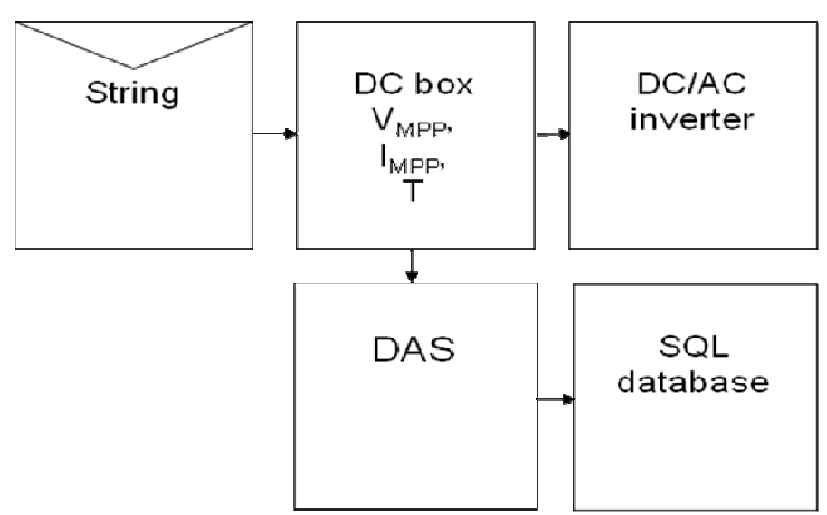

Figure 3 Layout of the DC monitoring system

The majority of measurements is taken in one second intervals. DC voltages, currents and modules temperatures are measured on string levels. AC RMS voltages and currents are measured on an inverter level. Special attention was given to irradiance measurements. Two Kipp\&Zonen CMP11 broadband pyranometers were installed to measure horizontal and plane of array irradiance. Simplified layout of the METEO subsystems was shown in Figure 4.

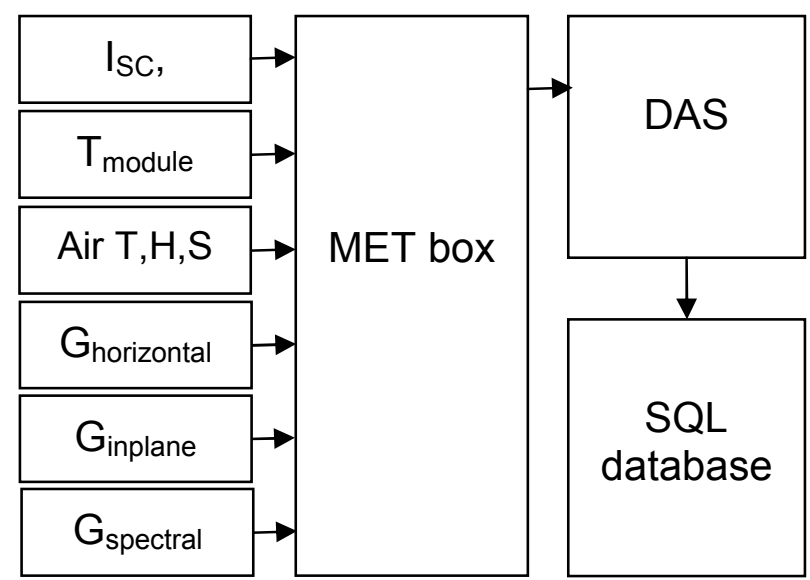

Figure 4 Layout of the METEO monitoring system.

PV modules are spectrally selective devices. Their spectral sensitivity is technology dependent. Spectral effects can be observed in particular for wide band-gap thin film devices. To investigate this, EKO MS-700 spectroradiometers were installed in plane of array to provide spectral irradiance measurements. Accurate intensity and spectral distribution of the sunlight allows to increase accuracy of prediction of the available energy for variety of $\mathrm{PV}$ device. The angular response of the modules differs from that of irradiance sensors (flat surface of the module glass vs. integration dome). As an alternative, short circuited 'reference modules' can be used to measure reference irradiance. This eliminates problems of angle response and spectral mismatch. To be able to calculate irradiance from short circuit current, an initial module calibration is needed. Figure 5 shows setup for reference irradiance sensors at Gent.

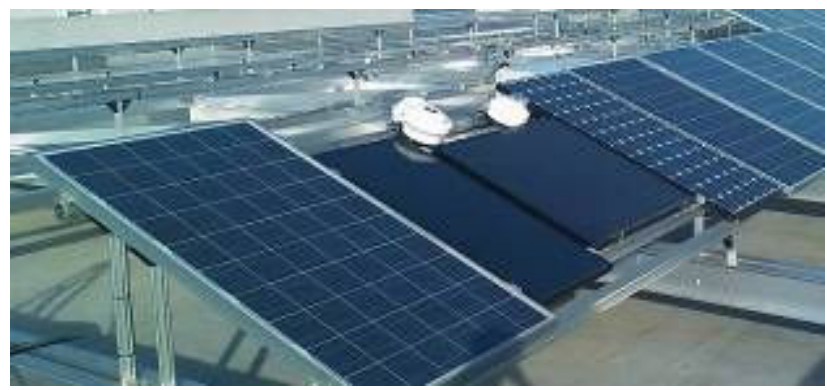

Figure 5 Dedicated reference modules and irradiance sensors installed at Gent.

Module temperature has a significant influence on its efficiency and thus is monitored on selected modules in each string. Thermal energy transport between the module and environment depends on mounting structure, irradiance, ambient temperature, humidity, wind speed and direction. All those parameters are monitored to provide accurate references for system performance analysis. All measurements are stored in a mySQL database to provide effective way of data analysis.

\section{ANALYTIC TOOLS}

Performance ratio $(P R)$ is a well known parameter used to describe the quality of a PV plant. The performance ratio $P R$ is the ratio of $P V$ energy actually produced to the energy theoretically available. It is relatively siteindependent, at least as far as there is no primary influence. It is also independent of system size. It indicates the overall losses due to the module temperature, incomplete utilization of irradiance, system component inefficiencies, component failures, wiring, inverter inefficiency, mismatch. Equation (1) presents how the performance ratio is calculated in this paper.

$$
P R=\frac{Y_{f}}{Y_{r}}
$$

where:

$$
\begin{aligned}
& Y_{f} \text { - final yield } \\
& Y_{r} \text { - reference yield }
\end{aligned}
$$

The reference yield represents the theoretically available energy per time period what defines the solar radiation resource for the PV system. It is a function of the location, orientation of the PV array, and month-to-month and yearto-year weather variability. Equation (2) presents how the reference yield is calculated.

$$
Y_{r}=\frac{H}{G}
$$

where:
$\mathrm{H}$ - total in-plane irradiance
G- reference irradiance $1000 \mathrm{~W} / \mathrm{m}^{2}$ 
Final yield represents the number of hours that the PV array need to operate at the standard test condition to provide the same energy as was provided to the grid by the system. The $Y_{f}$ normalizes the energy produced with respect to the system size to allow comparison of the energy produced by PV systems of differing size. Equation (3) presents how the final yield is calculated.

$$
Y_{f}=\frac{E}{P_{0}}
$$

where:

$$
\begin{aligned}
& \text { E- energy injected to the grid } \\
& \mathrm{P}_{0} \text { - nominal power of the installed PV array }
\end{aligned}
$$

As the aim of followed analysis is technology intercomparison, it is desired to cancel influences of the inverter efficiency, albeit it is impossible to exclude the influence of the maximum power tracker completely. To do so it is better to use array yield. Array yield represents the number of hours that the PV array need to operate at the standard test condition to provide the same energy as was provided to the inverter. Equation (4) presents how the array yield is calculated.

$$
Y_{A}=\frac{E_{A}}{P_{0}}
$$

where:

$$
\begin{aligned}
& E_{A^{-}} \text {energy injected to the inverter } \\
& P_{0} \text { - nominal power of the installed } P V \text { array }
\end{aligned}
$$

Energy of the array is equal to summarized DC power over time interval. Equation (5) presents how the energy of the array is calculated.

$$
E_{A}=\int P_{D C} d t
$$

All of above values are integrated over the time, Due to that temporal distribution of performance parameters is being lost. To avoid that, instantaneous, normalized array power $P_{n}$ can be used. Equation (6) presents how the normalized power of the array is calculated.

$$
P_{n}=\frac{\frac{P_{D C}}{G i}}{\frac{P_{D C 0}}{G_{0}}}=\frac{P_{D C}}{P_{D C 0}} \cdot \frac{G_{0}}{G_{i}}
$$

In addition, normalized array current $\left(I_{n}\right)$ and voltage $\left(V_{n}\right)$ can be calculated. Equations (7) presents how normalized array current is calculated.

$$
I_{n}==\frac{\frac{I_{D C}}{G_{i}}}{\frac{I_{D C_{0}}}{G_{0}}}=\frac{I_{D C}}{I_{D C 0}} \cdot \frac{G_{0}}{G_{i}}
$$

Equations (8) presents how normalized array voltage is calculated.

$$
V_{n}=\frac{V_{D C}}{V_{D C 0}}
$$

\section{RESULTS}

\section{Reference conditions}

Reference solar irradiance measurements have the highest influence on PV modules performance. The data seen by the systems is presented for Gent and Rostock in Figure 6 and Figure 7.

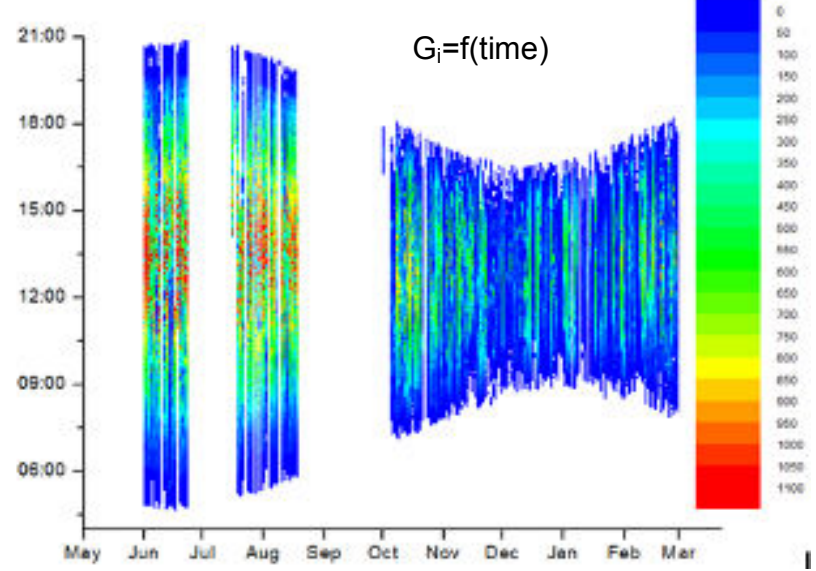

Figure 6 Temporal characteristic of the inplane irradiance at Gent(Belgium).

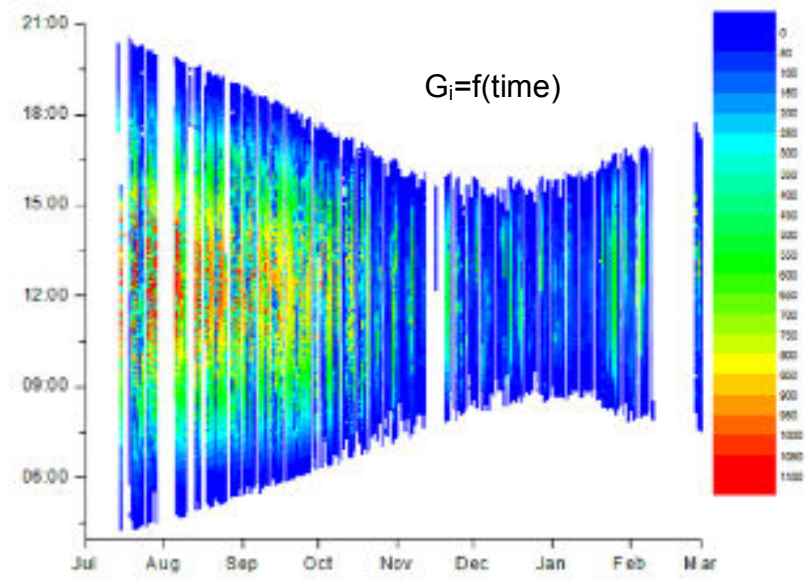

Figure 7 Temporal characteristic of the inplane irradiance at Rostock(Germany).

Interruptions in systems operation have occurred due to some initial problems and some intermediate work to be done at the systems. These will affect the irradiance distributions to varying extent. Gent's measurements were not available during part of the summer and early autumn months, what explains lower fraction of high power irradiation in the absolute irradiation distributions, which are shown in Figure 8 and Figure 9 


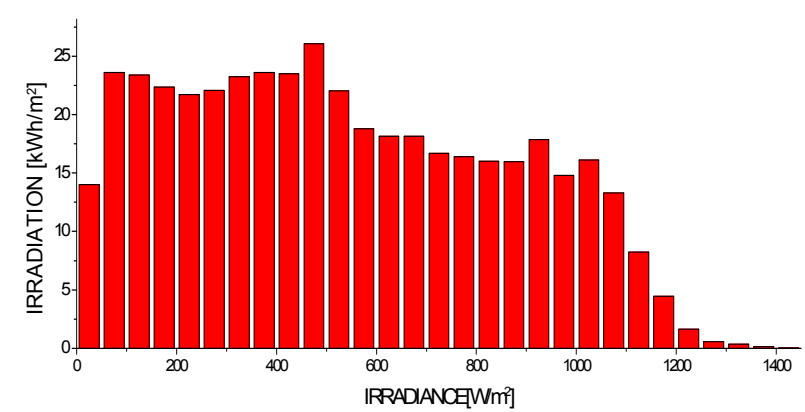

Figure 8 Distribution of the irradiation at Gent.

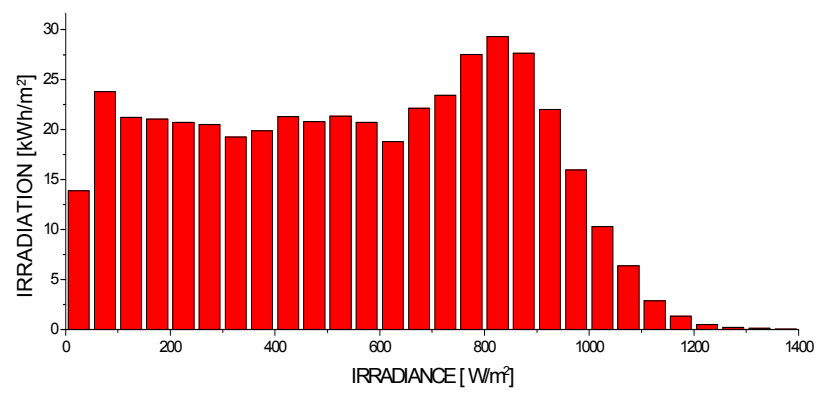

Figure 9 Distribution of the irradiation at Gent. Figure 9

As shown in Figure 8 and Figure 9, systems were performing under fairly wide range of irradiances. The operating period is not a full year, thus the winter months may contribute disproportionally (low irradiance was dominating especially at Gent).

Unluckily for PV devices, increase of irradiance cause increase of ambient temperature and decrease of the humidity. These condition limit heat transport. For most of the summer time, humidity is the highest in the morning and gets lower during a day. For most of the winter time humidity stays high all day long. Figure 10 and Figure 11 demonstrate correlations of temperature, irradiance and humidity for specified locations.

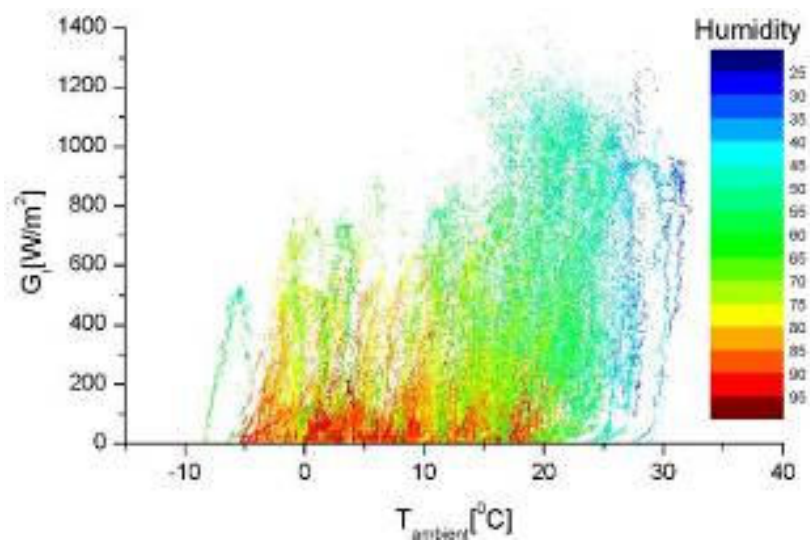

Figure 10 Relations between ambient temperature, irradiance and relative humidity at Gent.

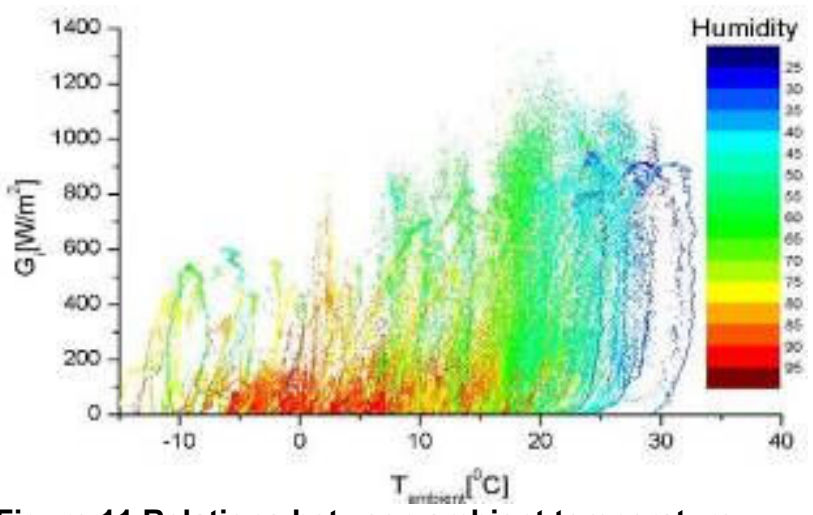

Figure 11 Relations between ambient temperature, irradiance and relative humidity at Rostock.

\section{Modules performance}

An initial analysis of different modules technologies performance was done to identify further optimisation potential. Normalized array power $\left(P_{n}\right)$ is presented as the function of date and daytime. This sort of data presentation allows to show short term (hourly) as well as long them(day by day) variations in module performance. Five different technologies were tested. Used technologies were listed in Table 1.

\begin{tabular}{|l|c|c|c|c|c|}
\hline & \multicolumn{2}{|c|}{ crystalline } & \multicolumn{3}{c|}{ thin films } \\
\hline technology & $\mathrm{p}-\mathrm{Si}$ & $\mathrm{m}-\mathrm{Si}$ & $\mu \mathrm{a}-\mathrm{Si}$ & $\mathrm{CIS}$ & $\mathrm{a}-\mathrm{Si}$ \\
\hline
\end{tabular}

Table 1 Investigated module technologies.

At first polycrystalline silicon modules were investigated. Figure 12 and Figure 13 shows temporal variations in module normalized power factor .

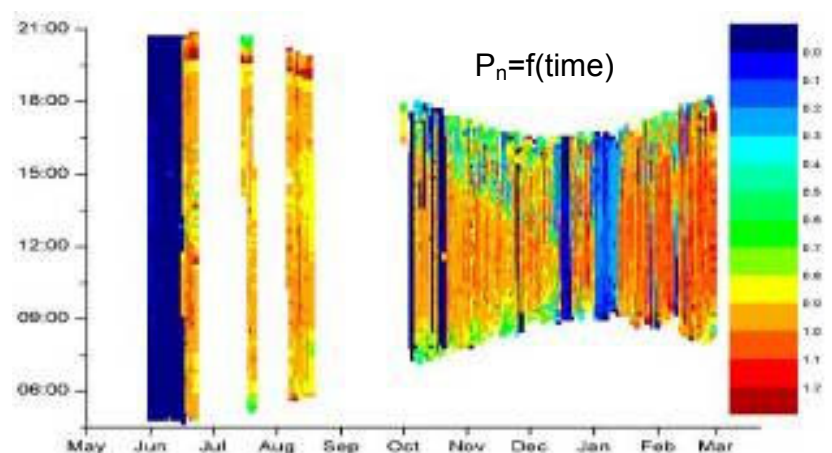

Figure 12 Temporal variation of normalized power factor $\left(P_{n}\right)$ for polycrystalline silicon modules installed at Gent. 


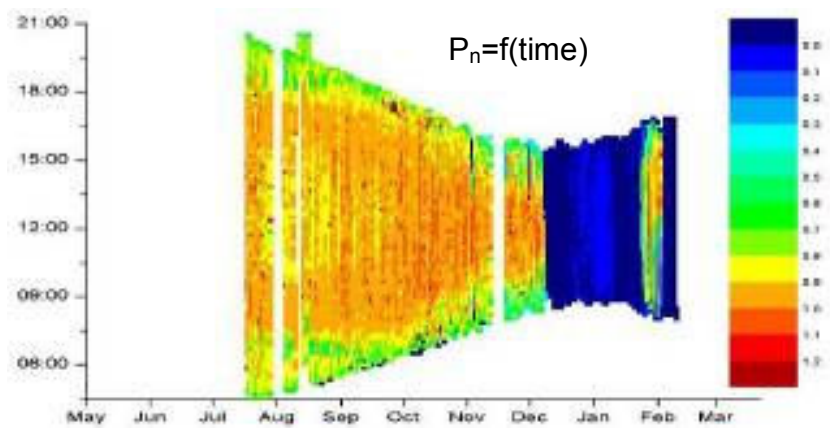

Figure 13 Temporal variation of normalized power factor $\left(P_{n}\right)$ for polycrystalline silicon modules installed at Rostock.

White gaps in the plot represent times when the DC system monitoring was not available due to communication problems. Continuous navy blue colour represents time when array was isolated from the inverter while DC monitoring system was working (modules needed to be exchanged due to a recall of the manufacturer). Gent data being heavily fragmented, it can be seen that in both locations $\mathrm{p}$-Si modules were performing well. It is also noticeable that the performance of $\mathrm{p}$-Si modules is lower in high irradiances (see Figure 14) . There is an noticeable drop in $P_{n}$ for irradiance above $700\left[\mathrm{~W} / \mathrm{m}^{2}\right]$. It happens due to increase of module temperature, as shown in Figure 15. This effect disappears once temperature corrections are applied.

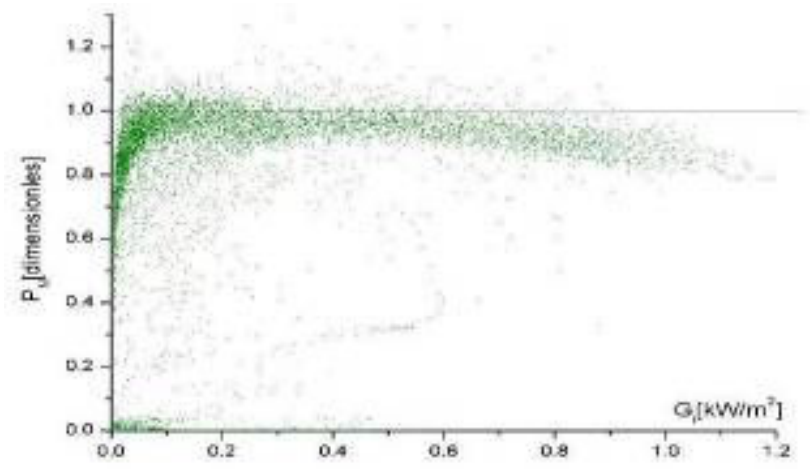

Figure $14 \mathrm{p}$-Si normalized maximum power point as the function of irradiance

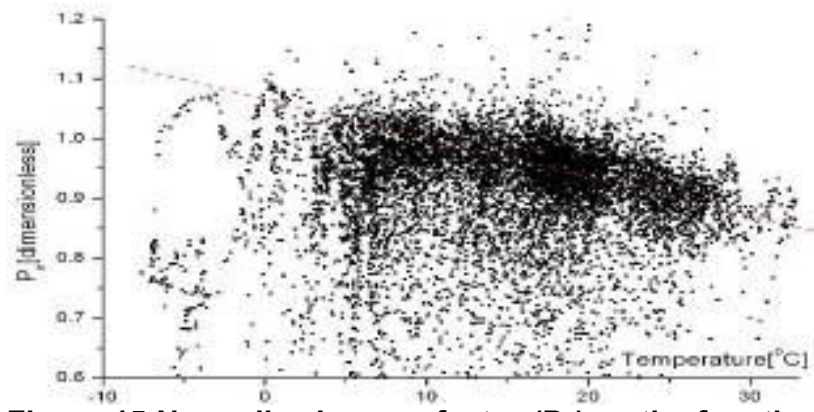

Figure 15 Normalized power factor $\left(P_{n}\right)$ as the function of temperature for polycrystalline silicon modules installed at Gent.
Separate plots of maximum power point voltage and current, shown in Figure 16, demonstrate a reducing influence of the temperature on the $\mathrm{p}$-Si array output voltage and power.

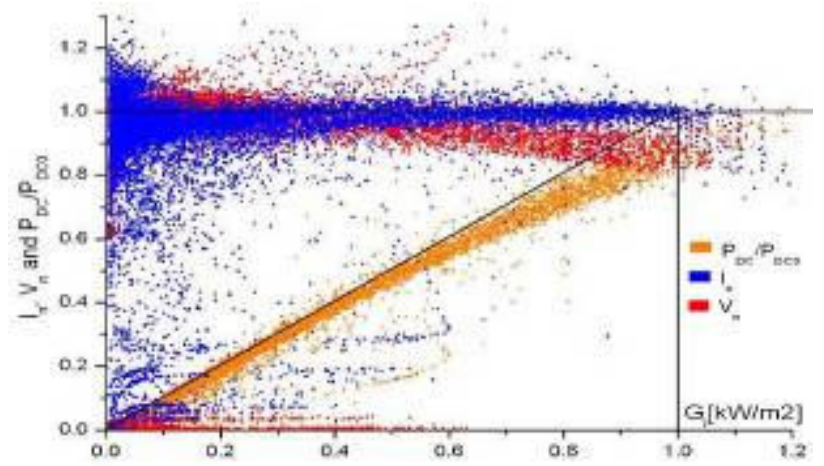

Figure $16 \mathrm{p}-\mathrm{Si}$ normalized maximum power point voltage and current as the function of irradiance.

Polycrystalline modules may give lover than expected energy yield once installed in extremely hot climates. Regardless of that $\mathrm{p}-\mathrm{Si}$ modules offer high reliability and high level of performance. Monocrystalline modules were performing similarly to polycrystalline. Figure 17and Figure 18 present normalized parameters for polycrystalline modules. Influence of the temperature is lower than it was for $\mathrm{p}$-Si modules.

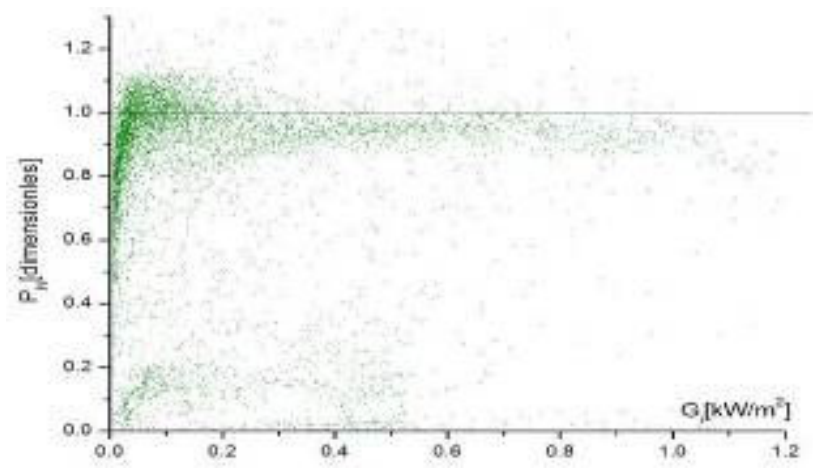

Figure $17 \mathrm{~m}$-Si normalized maximum power point as the function of irradiance.

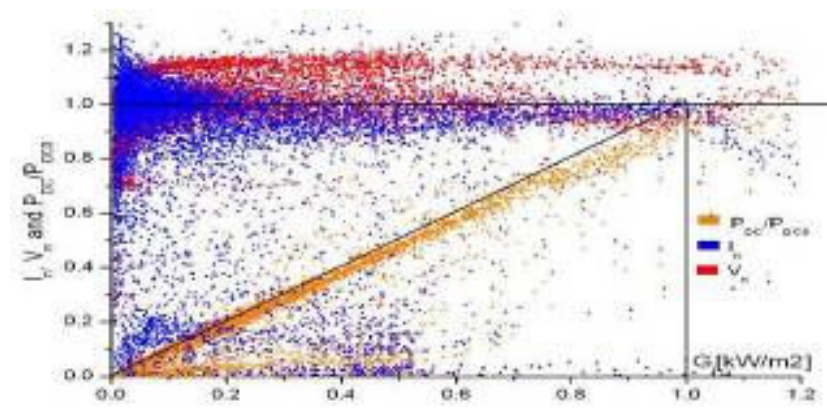

Figure $18 \mathrm{~m}$-Si normalized maximum power point voltage and current as the function of irradiance. 
Thin film modules are less established technologies. In general, under low irradiance, all of tested thin film modules were performing less efficient than crystalline, which is rather strange as it contradicts what has been found in module testing. This would be due to matching the technologies to the inverters or the ability of the inverter to control thin film devices efficiently. The performance increases continuously with the irradiance. Temporal distribution of $\mathrm{P}_{\mathrm{n}}$ for $\mu \mathrm{a}-\mathrm{Si}$ heterostructure array was shown in Figure 19.

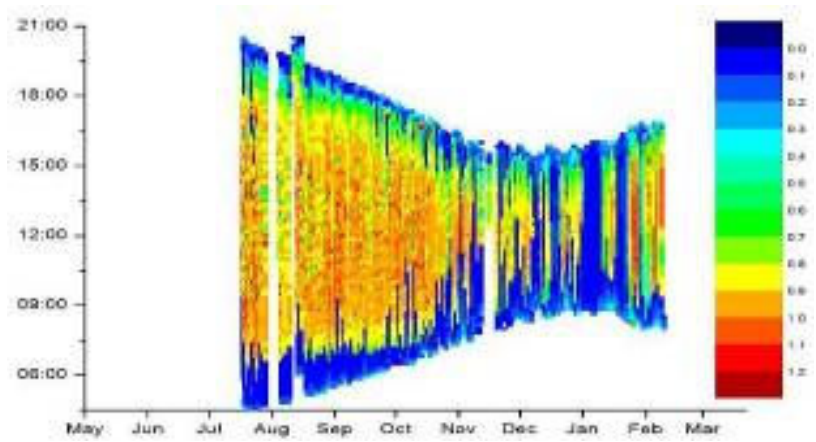

Figure 19 Temporal variation of performance of $\mu \mathrm{a}-\mathrm{Si}$ heterostructure array installed at Rostock.

Performance of amorphous silicon roof integrated modules was presented in Figure 20 and Figure 21.

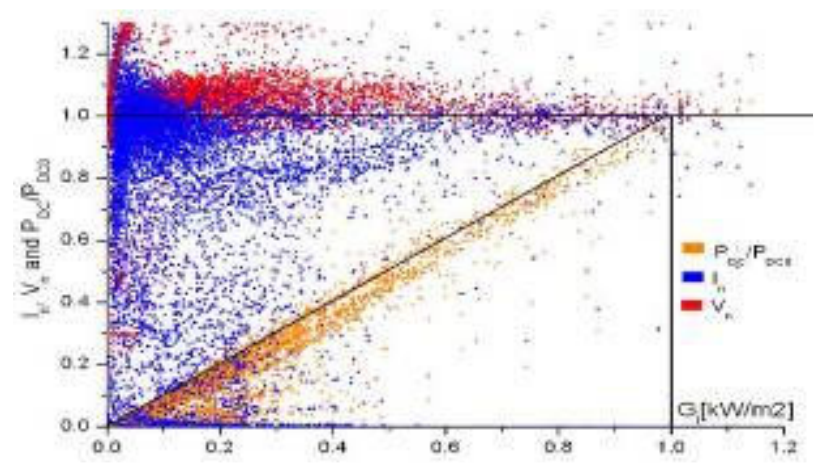

Figure 20 a-Si normalized maximum power point voltage and current as the function of irradiance.

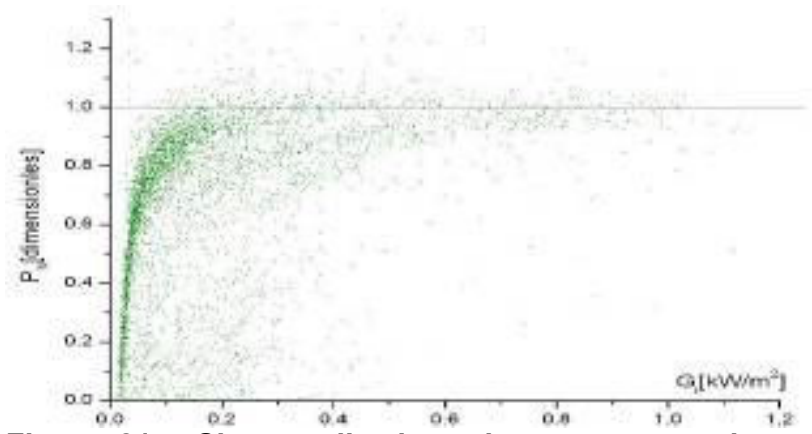

Figure 21 a-Si normalized maximum power point as the function of irradiance.
The most problematic technology to date is CIS. Its low light efficiency seems to be the worst of all systems. This disagrees with what has found from module monitoring and thus is likely to be an integration issue. Further investigations are currently being conducted on the reasons for this, with a likely candidate being the voltage window of the inverter not being optimally utilized by the system design.

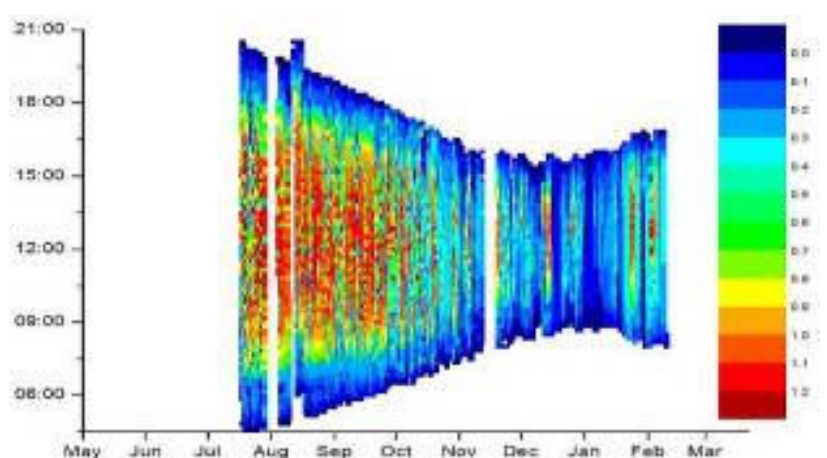

Figure 22 Temporal variation of performance of CIS array installed at Rostock.

\section{CONCLUSIONS}

A scientifically instrumented, large scale test of photovoltaic technologies for integrating into roof top systems has been demonstrated. The complexity of the system and the financial crises have introduced some delays and some issues in the system built. It is shown that the systems as a whole work well but that there is further room for improving the performance of the systems. The main issue seems to be the matching of technologies to the inverter specifications, as some of the observations here contradict with those made on module monitoring. The work is ongoing and more detailed results will be published when appropriate.

\section{ACKNOWLEDGEMENT}

This work is fully funded by IKEA and is a part of company investigations in area of utilizing new technologies to enhance sustainability of energy resources.

\section{REFERENCES}

[1] S. Ransome, "A review of $\mathrm{kWh} / \mathrm{kW}_{\mathrm{p}}$ measurements, analysis and modelling", Twenty third EUPVSEC, 2008, pp. 2795-2800.

[2] S.Ransome, "Array performance analysis using imperfect input data", Twenty third EUPVSEC, 2008, pp.3187-3191

[3] M.Strobel, T.R.Betts, G.Friesen, H.G.Beyer, R.Gottschalg, "Uncertainty in photovoltaic performance parameters- dependence on location and material", Solar Energy Materials and Solar Cells, 93(6-7), March 2009, pp 1124-1128 